\title{
Changes in the behavioral and immuno- logical parameters of the mollusk Biomphalaria tenagophila induced by disruption of the circadian cycle as a consequence of continuous illumination
}

I. Waissel ${ }^{1}$, J.R. M ineo ${ }^{2}$ and C.L. Natal ${ }^{1}$

\author{
Departamentos de ${ }^{1}$ Ciências Fisiológicas and \\ 2Patologia, Universidade Federal de Uberlândia, \\ U berlândia, MG, Brasil
}

\section{Correspondence}

C.L. Natal

Departamento de Ciências

Fisiológicas

Universidade Federal de Uberlândia

Av. Engenheiro Diniz, 1178

38401-136 U berlândia, MG

Brasil

Received February 10, 1999 Accepted September 22, 1999

\section{Abstract}

In the present investigation we studied some behavioral and immunological parameters of adult gastropod mollusk, Biomphalaria tenagophila, which have been reproducing for several generations under laboratory conditions. One group of gastropods was kept on a 14-h light/10-h dark cycle, corresponding to a regular circadian cycle, and another group was exposed to continuous light for $48 \mathrm{~h}$. Animals were studied along (behavioral groups) or immediately after (immunological groups) $48 \mathrm{~h}$ of regular circadian cycle or continuous light conditions. Stopping/floating, dragging and sliding were the behavioral aspects considered $(\mathrm{N}=20$ for regular cycle; $\mathrm{N}=20$ for continuous illumination) and number of hemocytes/ $\mu$ l hemolymph was the immunological parameter studied $(\mathrm{N}=15$ for regular cycle, $\mathrm{N}=14$ for continuous illumination). Animals under continuous illumination were more active (sliding $=33$ episodes, dragging $=48$ episodes) and displayed a lower number of hemocytes $(78.0 \pm 24.27 / \mu \mathrm{l})$ when compared with mollusks kept on a regular circadian cycle (sliding $=18$ episodes, dragging $=27$ episodes; hemocytes $=157.6 \pm 53.27 / \mu \mathrm{l})$. The data are discussed in terms of neural circuits and neuroimmunological relations with the possible stressful effect of continuous illumination.

The concept of bi-directional communication between the neuroendocrine and immunological systems is increasingly accepted $(1,2)$. This concept rests on the results of studies of the effect of various stress conditions on the immunological system and of the presence of hormonal characteristics of the response to stress in cells of the immunological system.

Stress can be seen as the most important and complex body reaction to ensure sur- vival (3). The large amount of information accumulated about stress and the immunological system results almost exclusively from studies on mammals. In particular, the relationship between the hypothalamus-pituitaryadrenal axis and the immunological system has been intensely investigated (4). Among mammals, mice have been the animals most frequently investigated in neuroimmunology laboratories. On the basis of the results obtained with these rodents, knowledge has 
been obtained about the neuroimmunological system of other animals, including invertebrates. However, invertebrates show very wide diversity, representing about 2 million species distributed among different phyla.

Nevertheless, some studies have demonstrated common characteristics of the neuroimmunological system that are shared by many species in the animal kingdom. For example, the effect of the phenomenon of stress has also been observed in invertebrates $(5,6)$ and some modulators of the neuroendocrine system and its specific receptors have been detected in these animals $(3,7,8)$. These studies have suggested that not only is the immunological system affected by stress, but there is also an evolutionary line that makes the mechanisms of the immunological response to stress quite similar between invertebrates and vertebrates. Several types of molecules known to be involved in the complex neuroendocrineimmunoregulatory system of vertebrates have also been detected in several species of invertebrates, regardless of their position on the phylogenetic scale (3). Mollusks in particular present relatively complex neural and endocrine systems, although they lack organs such as the hypothalamus, the pituitary and the adrenals, i.e., they lack the major organs involved in the response to stress of vertebrates.

In mollusks, the major cells of the immunological system are the circulating hemocytes or amebocytes. Such cells are classified into two main groups, the hyalinocytes and the granulocytes. They are present in the hemolymph and body fluids of mollusks and they are defense cells since they encapsulate and phagocyte foreign pathogens (9). They also contain ACTH-like materials and biogenic amines such as adrenaline, noradrenaline and dopamine. Furthermore, a similar cascade of reactions occurs in vertebrates. Thus, incubation of hemocytes in medium containing molecules, such as corticotrophin releasing hormone (CRH-like), induces
ACTH-like molecule release, which in turn stimulates the release of biogenic amines by the hemocytes of mollusks (3). Several processes can stress an organism either in a natural manner (presence of a predator, etc.) or in an artificial manner such as exposure to cold, electric shock, etc. (10), thus creating an afferent signal for the defense system which will activate mechanisms of adaptation to the new environmental conditions. This response can be both behavioral and immunological. The disequilibrium in the fine adjustment between these neural, endocrine and immunological systems can be harmful to the organism and is of no evolutionary value, as is the case for auto-immune diseases.

The objective of the present study was to determine the possible effect of stress induced by continuous illumination on the behavior and immunological parameters of Biomphalaria tenagophila, a freshwater snail that is an important intermediate host for the parasite Schistosoma mansoni in South America.

Adult specimens (11) of Biomphalaria tenagophila (Orbigny, 1835) mollusks were obtained from the Department of Biology of the Federal University of Uberlândia where they have been reproducing for several generations.

Initially, forty animals were divided into an experimental group $(\mathrm{N}=20)$ and a control group $(\mathrm{N}=20)$. Each group was maintained in a glass aquarium $(50 \times 28 \times 35 \mathrm{~cm})$ containing water under identical physicochemical conditions at room temperature $\left(25^{\circ} \mathrm{C}\right)$ for three days of adaptation to the experimental situation and two days of observation. Before the experiments, the snails were treated for the hatching of Schistosome miracidia that might have infected them by exposure to light and to a temperature of $28^{\circ} \mathrm{C}$ provided by a $60-\mathrm{W}$ incandescent lamp located at a distance of $40 \mathrm{~cm}$ for $30 \mathrm{~min}$ (12). The animals were fed lettuce leaves ad libitum. During the two days of observation, a 
Panasonic M 9000 camera with a minimum luminous sensitivity of 3 lux was used to record the movements of the animals. The observations were recorded on cassette tapes during sessions of 20 consecutive min three times a day, at 8:00, 15:00 and 21:00 h. Luminosity was 200 lux during the day (8:00 and 15:00 h) and approximately 10 lux at night $(21 \mathrm{~h})$.

The filmed data were analyzed using the behavioral table of Jurberg $(13,14)$. The behaviors were quantified by summing the total number of each behavioral expression over a period of $120 \mathrm{~min}$ and the groups were compared statistically by the $\chi^{2}$ test, with the level of significance set at $\mathrm{P}<0.05$.

The control group was submitted to a natural light-dark cycle, with $14 \mathrm{~h}$ of light (about 160 lux) and $10 \mathrm{~h}$ of darkness (approximately $10 \mathrm{lux}$ ), whereas the experimental animals were exposed to $48 \mathrm{~h}$ of continuous illumination (200 lux).

Another group of 29 adult specimens obtained from the same source and housed under the same conditions as previously described was used for the immunological study. We used 29 adult specimens of Biomphalaria tenagophila (11) divided into an experimental group $(\mathrm{N}=14)$ and a control group $(\mathrm{N}=15)$.

The periods of adaptation ( 3 days) and experimentation ( 2 days), recording time and periods and all other variables analyzed in this study were selected on the basis of previous observations in our laboratory.

Hemolymph was obtained by puncturing the cephalopodal mass with a sterilized Pasteur pipette (15), transferred to a test tube and mixed. After blood cell mixing, a known volume of hemolymph was placed in a Neubauer chamber for hemocyte counts. The hemocytes of each mollusk were counted separately. Experiments were carried out in a double-blind way and data were analyzed statistically by the Student $t$-test, with the level of significance set at $\mathrm{P}<0.05$.

The test for miracidium contamination was negative for all animals.

In general, the animals submitted to disruption of the circadian rhythm showed higher locomotor activity. With respect to sliding behavior, the activity of the experimental animals (33 episodes) was higher than that of control animals (18 episodes) $(\mathrm{P}<0.05$, Table 1). Dragging behavior was also observed more frequently $(\mathrm{N}=48$ episodes) than in control animals $(\mathrm{N}=27$ episodes) $(\mathrm{P}<0.05$, Table 1). In agreement with locomotor behavior, control animals expressed greater stopping-floating behavior

Table 1 - Number of sliding, dragging, and stopping-floating episodes presented by the two groups of mollusks during the 2 days of the experiment, determined according to the behavioral table of J urberg $(13,14)$.

$* \mathrm{P}<0.05$ and $* * \mathrm{P}<0.001$ compared to control $\left(\chi^{2}\right.$ test).

\begin{tabular}{lcc}
\hline Behavior & $\begin{array}{c}\text { Circadian } \\
\text { cycle }\end{array}$ & $\begin{array}{c}\text { Continuous } \\
\text { illumination }\end{array}$ \\
\hline Sliding & 18 & $33^{*}$ \\
Dragging & 27 & $48^{*}$ \\
Stopping-floating & 120 & $71^{* *}$
\end{tabular}

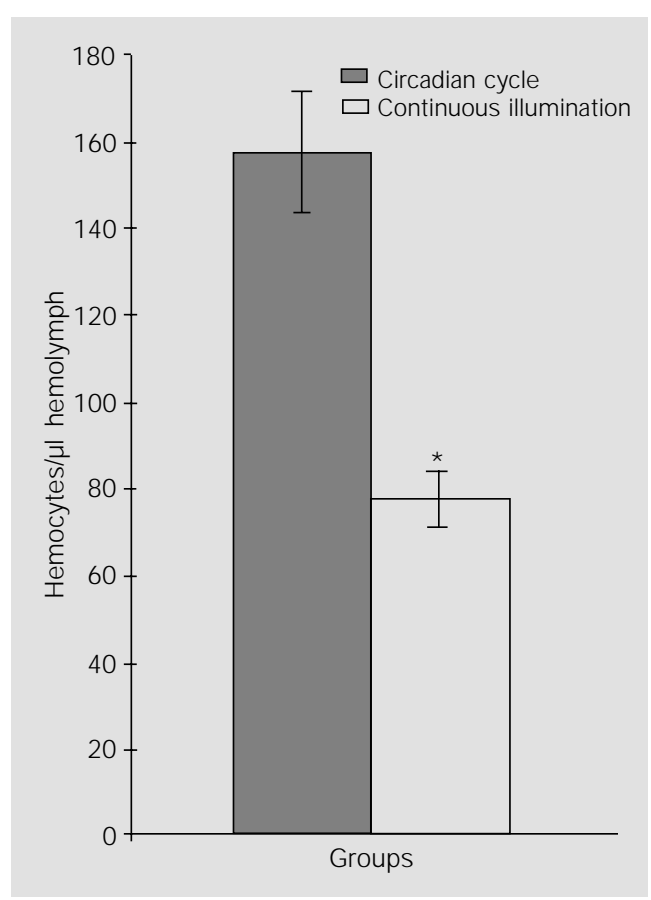

Figure 1 - Number of hemocytes per $\mu$ l hemolymph (mean \pm SEM) in animals kept under conditions of regular circadian cycle or of continuous illumination. $* \mathrm{P}<0.001$ compared to circadian cycle (Student t-test). 
( $\mathrm{N}=120$ episodes) than experimental animals $(\mathrm{N}=71$ episodes $)(\mathrm{P}<0.001$, Table 1$)$.

The animals submitted to disruption of the circadian rhythm presented a significant reduction $(\mathrm{P}<0.001)$ in hemocyte number (78 \pm 24.27 hemocytes/ $\mu$ l hemolymph) than the animals kept under a normal cycle (157.6 \pm 53.27 hemocytes/ $\mu$ l hemolymph). The results are shown in Figure 1.

The present data support the classical view that stress can affect the immunological response both in invertebrates and vertebrates $(3,10,16)$. Stress can increase or decrease the immunological ability depending on the time of stimulation and on the species, although in general it causes immunosuppression. A stressful stimulus applied to mollusks for prolonged periods of time may activate the defense mechanisms of the animal, which reacts according to the circumstance (10).

In the present study we observed aspects of the defensive system such as the behavioral and immunological response to conditions of continuous illumination in gastropod mollusks of the Biomphalaria tenagophila species. This condition, which disrupts the circadian cycle, may function as a stressful situation for these animals. In primates and rodents, exposure to light leads to alterations in the circadian cycles, which may provoke neuroendocrine variations, which in turn interfere with immunomodulation (16). An example is the circadian variation in leukocyte levels in humans. Although the total number of these cells is relatively constant throughout the day, the number of granulocytes and monocytes is higher during the daylight period and the number of lymphocytes is higher during the night. This variation is related to the type of adrenergic receptors on the surface of the cell membrane (17). These data led us to infer that a possible disruption of these circadian cycles may affect the number of cells during both the diurnal and the nocturnal cycle, and consequently alter the immune response of these animals.

Table 1 shows an increased expression of active motor behaviors such as sliding and dragging and a decreased expression of inactive motor behaviors such as stopping-floating in animals with a disrupted circadian cycle compared to control animals exposed to a regular cycle. Continuous light may activate changes in neuronal circuits, which may transform a behavior into another. Studies on adult mollusks of the genus Clione and on larvae of amphibians of the genus Xenopus have shown that separate although interlinked circuits are related to changes in behaviors such as floating to permit the animal to swim rapidly in the presence of environmental stimuli. In Clione, these circuits, denoted generators of central patterns, are located in the podal ganglia (18).

Figure 1 shows a reduced number of hemocytes in animals submitted to a disrupted circadian cycle compared to the animals exposed to a regular cycle. Inhibition of the immunological system by the neural system probably occurred under conditions of continuous illumination. Light is known to inhibit the transformation of serotonin to melatonin in mammals. Thus, the light that hits the retina stimulates the suprachiasmatic nucleus of the hypothalamus and results in increased serotonin levels and decreased melatonin levels. This neuromodulator inhibits corticotropin release and therefore in the presence of light there will be activation of the adrenal corticosteroid system through an increase in the serotonin/melatonin ratio (16). Although corticosteroids are immunosuppressive, serotonin is known to selectively activate $\mathrm{T}$ lymphocyte proliferation (19). Thus, hemocytes may be subjected to a more general regulatory system in which an increase in corticosteroid-like substances may lead to inhibition of the proliferation of these cells or even to their migration to organs outside the hemolymph. Although mollusks do not possess the hypothalamus-pituitaryadrenal axis involved in the above process, there must be a system functionally similar to this, since many of these hormones are found in their hemolymph and receptors for 
these substances were detected in their hemocytes (3). The data in Table 1 and Figure 1 show that the animals submitted to disruption of the circadian cycle presented greater mobility and lower hemocyte expression. It is possible to imagine that a type of circuit dedicated to each aspect of regulation may be involved in each case (20). Thus, continuous illumination may activate a motor circuit while at the same time deactivating a circuit related to the neuroimmunological axis. Another possibility is that a neuromodulator is involved in these circuits, activating one and deactivating the other. For example, serotonin is known to activate the production of corticosteroids, which are immunosuppressive agents. In the mollusk Clione this sub- stance is involved in the transformation of a flight behavior by changing slow swimming to rapid swimming (18). Our results permit us to suggest that the same may be occurring with the mollusks studied in the present investigation. A substance such as serotonin itself or a similar agent whose levels are increased by light may simultaneously cause the decrease in number of hemocytes in the hemolymph and the increase in the sliding/ dragging behaviors observed in the animal submitted to continuous illumination. In future research it should be very interesting to evaluate how these monoamines, especially serotonin, are actually involved in such modulatory mechanisms of behavioral and immunological responses.

\section{References}

1. Rabin BS, Cohen S, Ganguli R, Lysle DT \& Cunnick JE (1989). Bidirectional interaction between the central nervous system and the immune system. Critical Reviews in Immunology, 9: 279-312.

2. Ader R, Felten D \& Cohen N (1990). Interactions between the brain and the immune system. Annual Review of Pharmacology and Toxicology, 30: 561-602.

3. Ottaviani E \& Franceschi C (1996). The neuroimmunology of stress from invertebrates to man. Progress in Neurobiology, 48: 421-440.

4. Bateman A, Singh A, Kral T \& Solomon S (1989). The immune-hypothalamic-pituitary-adrenal axis. Endocrine Reviews, 10: 92-112.

5. Stefano GB \& Catapane EJ (1977). The effects of temperature acclimation on monoamine metabolism. J oumal of Pharmacology and Experimental Therapeutics, 203: 449-456.

6. Stefano GB, Hiripi L \& Catapane EJ (1978). The effect of short- and long-term temperature stress on serotonin, dopamine and norepinephrine metabolism in molluscan ganglia. J oumal of Thermal Biology, 3: 79-83.

7. Stefano GB, Leung $M K$, Zhao $X \&$ Scharrer $B$ (1989). Evidence for the involvement of opioid neuropeptides in the adherence and migration of immunocompetent invertebrate hemocytes. Proceedings of the National Academy of Sciences, USA, 86: 626-630.
8. Stefano GB, Cadet P \& Scharrer B (1989). Stimulatory effects of opioid neuropeptides on locomotory activity and conformational changes in invertebrate and human immunocytes: Evidence for a subtype of $\delta$ receptor. Proceedings of the National Academy of Sciences, USA, 86: 6307-6311.

9. Sminia T \& van der Knaap WPW (1987). Cells and molecules in molluscan immunology. Developmental and Comparative Immunology, 11: 17-28.

10. Stefano GB, Cadet P, Dokun A \& Scharrer B (1990). A neuroimmunoregulatory-like mechanism responding to stress in the marine bivalve Mytilus edulis. Brain, Behavior and Immunity, 4: 323-329.

11. Paraense WL (1970). Planorbídeos hospedeiros intermediários do Schistosoma mansoni. In: Cunha AS (Editor), Esquistossomose mansoni. Edusp, São Paulo.

12. Standen OD (1951). The effects of temperature, light and salinity upon the hatching ova of Schistosoma mansoni. Transactions of the Royal Society of Tropical Medicine and Hygiene, 45: 221-241.

13. J urberg P (1995). Etologia. In: Barbosa FS (Editor), Tópicos em Malacologia Médica. Editora Fiocruz, Rio de J aneiro.

14. J urberg P, Schall VT, Barbosa J V, Gatti MJ \& Soares MS (1987). Behavior of Biomphalaria glabrata, the intermediate host snail of Schistosoma mansoni, at different depths in water in laboratory conditions. Memórias do Instituto Oswaldo
Cruz, 82: 197-208.

15. Michelson EH (1966). Specificity of hemolymph antigens in taxonomic discrimination of medically important snails. J ournal of Parasitology, 52: 466-472.

16. Roberts JE (1995). Visible light induced changes in the immune response through an eye-brain mechanism (photoneuroimmunology). J ournal of Photochemistry and Photobiology, 29: 3-15.

17. Suzuki S, Toyabe S, Moroda T, Tada T, Tsukahara A, Hai T, Minagwa $M$, Maruyama S, Hatakeyama K, Endoh K \& Abo T (1997). Circadian rhythm of leucocytes and lymphocyte subsets and its possible correlation with the autonomic nervous system. Clinical and Experimental Immunology, 110: 500-508.

18. Arshavsky YI, Orlovsky GN, Panchin YV, Roberts A \& Soffe SR (1993). Neuronal control of swimming locomotion: analysis of the pteropod mollusc Clione and embryos of the amphibian Xenopus. Trends in Neurosciences, 16: 227-233.

19. Rao ML, Miller-Oerlinghausen $B$, Mackert A, Stieglitz RD, Strebel B \& Volz HP (1990). The influence of phototherapy on serotonin and melatonin in non-seasonal depression. Pharmacopsychiatria, 23: 155-158.

20. Morton DW \& Chiel HJ (1994). Neural architectures for adaptive behavior. Trends in Neurosciences, 17: 413-420. 